\title{
La comunicación tras el terremoto en Ecuador: la responsabilidad de informar y el negocio de entretener
}

\author{
Communication after the earthquake in Ecuador: \\ responsibility to inform and the entertainment business
}

\author{
Autores \\ VIDAL FERNÁNDEZ, Pablo. Mgter \\ URL ORCID http://orcid.org/0000-0002-8899-0250 \\ Profesor contratado en el área de Marketing de la Facultad de Ciencias de la Comunicación de la Universi- \\ dad Laica Eloy Alfaro de Manabí- Ecuador \\ pablo.vidal@uleam.edu.ec
}

\section{ZAMBRANO BARCIA, Andrea. Mgter}

Profesora contratada en el área de Marketing de la Facultad de Ciencias Administrativas de la Universidad Laica Eloy Alfaro de Manabí- Ecuador andrea.zambrano@uleam.edu.ec

\author{
PÉREZ MARTÍNEZ, Javier. Mgter \\ URL ORCID http://orcid.org/0000-0002-0718-0118 \\ Docente Investigador de la Universidad Técnica de Esmeraldas Luis Vargas Torres - Ecuador \\ Doctorando de la Universidad Autónoma de Madrid \\ javier.perez@utelvt.edu.ec jperezmtnez@hotmail.com
}

\section{RESUMEN}

El 16 de Abril de 2016, Ecuador sufrió uno de los terremotos más devastadores de su historia, con una magnitud de 7.8 en la escala de Ritcher. En mitad del caos y la desesperación, los medios de comunicación difundían y transmitían en directo las imágenes, las voces y los relatos de la catástrofe.

El presente artículo explica la gestión de los medios de comunicación ante situaciones de crisis, y como la existencia de la creciente saturación de la información, o también conocida como infoxicación, o la necesidad de conmover y lograr tener el mayor alcance posible para así lograr diferentes efectos, tales como las ayudas económicas y humanitarias, hacen que la visión del suceso cambie radicalmente de un medio de comunicación a otro.

A pesar de lo inmersa que vive la sociedad en la cultura digital, la cual nos brinda herramientas de curación de contenidos con el fin de filtrar información, se ha constatado que incluso teniendo al alcance este

\section{ABSTRACT}

On April 16, 2016, Ecuador suffered one of the most devastating earthquakes in its history, with a magnitude of 7.8 on the Richter scale. In the midst of chaos and despair, the media disseminated and broadcast live images, voices and stories of the disaster. This article explains the management of the media in situations of crisis, and the existence of increasing saturation of information, or also known as infoxication, or the need to move and manage to have the widest possible scope in order to achieve different effects, such as economic and humanitarian aid make the vision of the event change radically from one media to another. Despite the immersed living society in the digital culture, which gives us tools of content curation in order to filter information, it has been found that even having available these resources, the earthquake in Ecuador meant a collapse level management information generating chaotic scenarios in the distribution of both the rescuers and the 
tipo de recursos, el terremoto en Ecuador supuso un colapso a nivel de gestión de información generando escenarios caóticos en la distribución tanto de los equipos de rescate como de la difusión de noticias a la población durante los primeros días de la catástrofe.

\section{PALABRAS CLAVE}

Medios de comunicación, cultura digital, gestión de información, comunicación en crisis

\section{INTRODUCCIÓN}

El terremoto ocurrido en Ecuador la noche del 16 de abril del presente año con epicentro en Muisne, provincia de Esmeraldas, ha devuelto a la coyuntura social la gestión de la comunicación y el tratamiento informativo bajo contextos de crisis y emergencia. Los medios de comunicación coexisten con la exigencia de la inmediatez y actualización de la información. Aquella exigencia aumenta bajo la alarma social de una catástrofe y el manejo comunicacional conlleva una mayor complejidad a la hora de filtrar la información y digerirla para su difusión. La carrera por informar es susceptible de convertirse en un esprint por la imagen de la espectacularidad, siempre bajo la excusa y aquiescencia de los gestores que supuestamente impone el rating (Cerbino, 2006: 48). La responsabilidad de comunicador social se multiplica bajo estos contextos y se torna un desafío.

Se observan algunos obstáculos para la comunicación en crisis que suelen ser agravamientos de los procesos de comunicación de lo cotidiano. A pesar de los pocos estudios empíricos que se han realizado centrados en la comunicación en desastres podemos inducir, considerando el trabajo de Mata Martins y Paris Spink (2015), que el uso de las tecnologías de la comunicación ayudaría a reducir las consecuencias de este tipo de contingencias. Además de los elementos tecnológicos y las redes de información existen otros factores de gran dissemination of news to the population during the first days of the disaster.

\section{KEYWORDS}

Media, digital culture, information management, crisis communication

relevancia que atender y poder atenuar los perjuicios en la comunicación tras un desastre. Es el caso de factores del campo jurídico, organizacional, político, social y psicosocial; así como, artificios mediáticos y culturales supeditados a una sociedad del espectáculo.

Teniendo en cuenta la forma de selección y construcción mediática, sin olvidar los vacíos de varios elementos que se asocian con el objeto de estudio, este trabajo aspira a un sucinto análisis y aporte tras la experiencia vivida y la recepción mediática tratamiento y manejo de la información. De acuerdo a ello, se va a enfocar el diagnóstico de la comunicación posterior al desastre en el contexto del litoral ecuatoriano. A continuación, se incorpora el concepto de espectáculo en la comunicación de masas y algunas cuestiones retóricas para abordar el análisis del tratamiento. En suma, se ordena un marco preciso para incentivar una reflexión sobre la comunicación en crisis y su planificación en la contingencia, para terminar con valoraciones e indagaciones sobre el perjuicio de hacer del trauma un espectáculo en lugar de brindar un servicio público a la sociedad para superar el desastre.

\section{COMUNICACIÓN EN CRISIS}

Uno de los conceptos más importantes de este estudio es la comunicación y su importancia en tiempos de crisis o catástrofes. Es por ello que es necesario conocer la defini- 
ción de comunicación, según Fernández y Gordon (1992: 3) "la palabra comunicación proviene del latín comunis común. Al comunicarnos pretendemos establecer algo en común con alguien o, lo que es lo mismo, tratamos de compartir alguna información, alguna idea o actitud".

Por otra parte Giraud (1972: 11) explica que el proceso de la comunicación "implica un objeto, una cosa de lo que se habla o referente, signos, y, por lo tanto, un código, un medio de transmisión $y$, evidentemente un destinador y un destinatario".

Z.M.Zorín (2012), define la comunicación como "todo proceso de interacción social por medio de símbolos y sistema de mensajes. Incluye todo proceso en el cual la conducta de un ser humano actúa como estímulo de la conducta de otro ser humano". Se trata de un proceso dialógico de infinidad de significaciones. Además de considerar la comunicación como un proceso semiótico de constante interpretación (Karam, 2011), se debe precisar sobre la comunicación que nos ocupa, la comunicación en crisis.

Existen muchas definiciones de comunicación, en su mayoría son concernientes a la relación entre en un emisor y un receptor. Sin embargo, la comunicación en tiempos de crisis es descrita por varios autores y a continuación se citan con el fin de lograr un mayor entendimiento del presente artículo. Coombs y Holladay (2012) editan un extenso manual de comunicación en crisis (The handbook of crisis communication). Allí el mismo Coombs () introduce sus definiciones; de donde, de manera sucinta, se puede resumir la comunicación en crisis en el acopio, procesamiento y difusión de la información que se hace indispensable durante un caso de crisis. Para González Herrero (1998: 38):

"Es la capacidad de una organización de reducir o prever los factores de riesgo e incertidumbre respecto al futuro, de forma que se capacite a la misma para asumir de manera rápida y eficaz las operaciones de comunicación necesarias que contribuyan a reducir o eliminar los efectos negativos que una crisis puede provocar sobre su imagen y reputación."

En el caso de la gestión de la comunicación en tiempos de crisis según Piñuel (1997: 171) consiste en administrar dos vías de problema. Primero, "frenar la crisis sirviéndose de la comunicación para aportar reacciones efectivas frente al acontecimiento que la originó $y$, por otra, se trata de que la pérdida de crédito y de capital en imagen, ocasionada por la crisis, sea mínima".

De acuerdo a la Organización Panamericana de la Salud. En una emergencia la recopilación, producción y divulgación de información es un factor preponderante tanto interna como externamente de fuentes fiables. Si la información se produce y se circula a tiempo serán mayores las probabilidades de que las decisiones sean oportunas y efectivas.

Una situación de crisis o eventualidad hace llamado a la opinión pública, donde se relata el hecho, sus posibles causas y efectos vividos en el siniestro, la información se debe dar de manera rápida y con veracidad para evitar malos entendidos, o desinformar a la sociedad dando paso a la infoxicación, Marín (2000: 269) lo explica de la siguiente manera:

"La opinión pública demanda conocer el desarrollo de los acontecimientos y el tipo de decisiones que se adoptan para afrontarlos; siendo el hecho de tener que decidir bajo la presión del ritmo rápido de los acontecimientos, lo que obliga a implementar un abanico de acciones de comunicación para justificar esas decisiones $y$, al mismo tiempo, explicar los motivos y la incidencia de la crisis."

La información en un momento de emergencia o siniestro pasa a ser lo más impor- 
tante y deseado por las personas que buscan conocer la situación real de afectación para poder tomar decisiones o guiar su accionar, brindar ayuda a personas damnificadas, tener datos, cifras, informes de la situación, recomendaciones, entre otros. Por ello, la fuente de información que por lo general es dada por autoridades, organismos nacionales, personas afectadas, periodistas y demás, debe ser veraz; ya que podría provocar confusiones que pueden alterar a las personas que se encuentren dentro de la emergencia.

Cada actor dará información desde el punto de vista de su vivencia o área de conocimiento, generando su propio contexto de la magnitud del siniestro por ello, "siempre será imprescindible el relato minucioso de cómo la gente vivió ese momento, de lo que vio, oyó, sintió, supuso, imaginó y hasta soñó durante los días siguientes" (Camps y Pazos, 1996: 196); y es en el relato testimonial cuando puede derivarse hacia el espectáculo y la vulneración de derechos personales.

El impacto de imágenes o la forma de comunicar se convierte en un factor importante para la generación de ayudas nacionales e internacionales ante una catástrofe. En consecuencia, el rol del comunicador debe ser el ideal y adoptar estrategias que persuadan a las personas que reciben el mensaje a brindar su apoyo y a conocer lo que se está padeciendo. El apoyo de recursos internacionales en una emergencia es necesario y dependerá del tipo de siniestro o catástrofe en el caso de terremotos el talento humano y la tecnología en equipos de búsqueda y rescate permite salvar personas que aún se encuentra con vida entre los escombros. Además, la ayuda con víveres y agua permiten a los damnificados sobrevivir hasta que se tomen medidas internas y todos los servicios básicos se restablezcan y se logre una gestión eficiente de la emergencia que ayude a disminuir su impacto.

Isabel María Ruiz Mora y Antonio Castillo, son autores del octavo texto "La responsa- bilidad social como estrategia proactiva en la gestión de crisis. En este documento se refleja la importancia de que los periodistas y los medios de comunicación apliquen su responsabilidad social y formen parte del equipo de apoyo. Por tanto, entre los aspectos éticos más relevantes a los que se enfrentan los profesionales consiste en realizar su trabajo y brindar ayuda a evacuar gente si no existe aún la intervención de instituciones de emergencia. De no ser así, se podría ver afectada la credibilidad y humanidad de un informador, como es lógico y destacan Hight y Smyth (2003: 12): "Si el periodista se concentra en hacer su trabajo sin extender una mano a las víctimas, el público puede considerar esta acción moralmente inapropiada".

Los periodistas que viven estos momentos post catástrofe o crisis en el lugar de los hechos, son muy propensos a tener traumas psicológicos inmediatos o posteriores, para ello es importante su previa preparación y enviar equipo capacitado para cubrir este tipo de escenarios. Además como parte de su responsabilidad social también es el de impartir información veraz y mantener informada a la comunidad sobre su actuar post catástrofe y estar prevenido de riesgos futuros.

Existen diversas cualidades y conocimientos que debe poseer un comunicador en caso de desastres y la Organización Panamericana de la salud. En su libro "Gestión de la información y comunicación en emergencias y desastres", las presenta de la siguiente manera: Facilitador de diálogo, producir, analizar y sistematizar información, trabajar en equipo, bajo presión y en escenarios difíciles, elaborar e implementar estrategias y recursos de comunicación que respondan a las necesidades y demandas de los actores clave. 


\section{PLANIFICACIÓN EN LA CONTIN- GENCIA Y PREVISIÓN COMUNICATIVA}

La tierra mantiene procesos de cambios ecológicos y variación geológica. Estos fenómenos suponen posibles amenazas para las poblaciones y el medio ambiente (Brusi, 2008). Cuando suceden estos eventos se incrementa el riesgo y la vulnerabilidad de la población según el nivel de urbanización, el número de habitantes, las condiciones de construcción de los inmuebles, los servicios e infraestructuras y el grado de desarrollo de un país.

Ecuador es un país expuesto a potenciales peligros por causas naturales: erupciones, inundaciones, terremotos, tsunamis, etc; puesto que se trata de un país volcánico y costero donde impacta el fenómeno El Niño, y se encuentra situado en zona sísmica por la unión de las placas tectónicas de Nazca y del Pacífico (Secretaría Nacional del Gestión de Riesgos), conocida como el cinturón de fuego. Dado que los fenómenos naturales se producen de manera regular en el planeta y con graves consecuencias conviene pensar en la comunicación social en estos eventos a futuro, y de ese modo, trazar un plan estratégico.

Para los medios de comunicación nacionales o internacionales las primeras horas del desastre es un momento crucial, porque es muy difícil recopilar la información adecuada y poder garantizar que la misma sea clara, lo que las personas deseen saber y sobre todo que manifieste las necesidades que se tienen ante la catástrofe para ser satisfechas.

La planificación (recopilación, producción para el anuncio) es la base para que el manejo de la información que será emitida a los receptores sea adecuada y exitosa, sin embargo al ser incierto, es difícil contar con una planificación, para ello es fundamental estar preparados con listado de fuentes de información que puedan proporcionar datos, disponer de mapas, estadísticas de po blación, indicadores socio-económicos, datos históricos y otras investigaciones útiles sobre desastres que permitan comprender mejor el impacto de la emergencia. Además se debe emitir la información (cifras, imágenes, opiniones de expertos, testimonios de sobrevivientes, acciones de autoridades) a medios internacionales y organizaciones que puedan brindar ayuda humanitaria, de tal manera que refleje la magnitud de afectación, y la calidad de ayuda que están recibiendo.

Las catástrofes pueden darse por distintas causas, ya sean estas naturales o producto de la mano del hombre; por ello, algunas son previsibles y pueden buscarse soluciones o aplicarse prevenciones, pero en el caso de las imprevisibles generan incertidumbre porque se desconoce el momento de su acción. Bernardo y Pelliser indican que "cuanto mayor es la incertidumbre, mayores son las consecuencias y mayores las dificultades para trasladar los hechos al espacio y el tiempo de los medios" (Bernardo y Pelliser, 2010: 108). Ciertos desastres naturales no se pueden predecir, sin embargo, la naturaleza es sabia y tienen razón de ser, lo importante es estar preparados para que el impacto del desastre sea menor y no exista mayor afectación.

Existen políticas públicas elaboradas entorno a la prevención de riesgos ante desastres naturales, que muchas veces los seres humanos por su cultura dejan a un lado y no las aplican y cuando se presentan los eventos, actúan sin saber qué hacer, exponiéndose, así, a mayores daños o desgracias. De esta manera, el papel de la comunicación es muy importante no sólo durante o después de un desastre sino siempre. Habrá que mantener previsión para lograr llegar a la mayor cantidad de personas con programas de asistencia neurolingüística a través de medios de comunicación que permitan informar correctamente a la sociedad y lo- 
gren en ellos hacer conciencia de una planificación frente a la contingencia.

Ante distintos eventos que se han suscitado en un determinado lugar (terremotos, inundaciones, incendios forestales, tsunamis) se ha observado la intervención de medios de comunicación para informar a la ciudadanía cifras, sucesos, afectados, lugares de afectación, causas, efectos entre otros aspectos relevantes que son de suma importancia dar a conocer a la ciudadanía. Es importante señalar que en una emergencia la producción y circulación oportuna y transparente de información contribuye a generar confianza y credibilidad.

La comunicación y la gestión adecuada de la información en tiempos de catástrofes o riesgos como lo indica la cita conllevan una gran responsabilidad a los informantes, con el propósito de que la veracidad de los datos logre generar credibilidad en las personas que se enriquecen de su contenido. Ese contenido deberá provenir de fuentes especializadas o personas autorizadas a dar una respuesta ante una eventualidad. Por lo general, dependiendo del tipo de evento serán autoridades gubernamentales, técnicos especialistas, información científica, técnica y operativa; las mismas que permitirán a la comunidad conocer causas, efectos y decisiones que se toman tras los sucesos.

Ante un terremoto como vivió el Ecuador el 16 de abril, la información veraz y adecuada es lo que todo el país y el mundo entero demandaba. Así, poder conocer la realidad de las dos provincias con mayor afectación, y otros datos con distintos fines, brindar ayuda, estar prevenidos, entre otros. Analizando lo antes mencionado, es importante hacer énfasis en la relevancia de la comunicación en el mundo actual como fuente de conocimiento.

La comunicación ha evolucionado mucho en los últimos años gracias a la globaliza- ción y la tecnología, hoy en día la comunicación es cada vez más directa y segmentada, y permite llegar a masas en distintos lugares del mundo a través de las redes sociales.

Marshall Mcluhan es uno de los autores más conocidos a nivel mundial en la comunicación en masas por su obra The Gutenberg Galaxy: the making of photografic man (1962), y junto a su mentor Harold Innis señalan la comunicación de masas como la esencia de la civilización occidental.

El internet ha tenido un gran posicionamiento en el mundo y es una de las principales fuentes de obtención de información de cualquier índole, es por ello que se ha convertido en el principal medio de consulta definiéndose como la plataforma que acumula grandes cantidades de conocimientos, derivada de la gran cantidad de interacciones, investigaciones y la imaginación de los millones de usuarios que diariamente la consultan, trabajan o se divierten con ella.

En la actualidad las redes sociales se han convertido en uno de los medios de comunicación más utilizados por el ser humano por el impacto dinámico masivo, se define a la red social como un sistema abierto que encontramos en internet en el que un gran número de usuarios puede interconectar entre sí de forma dinámica posibilitando la potenciación de recursos que cada usuario posee. Tan importante supone la coordinación de una comunicación reflexiva como de la innovación de los actores sociales que pasan a ser divulgar en sus entornos (Comfort, 2007).

La comunicación del riesgo supone una medida oportuna para frenar las amenazas, evaluar y contener el miedo. "La disponibilidad de la información permite al público tomar decisiones informadas con respecto a los riesgos" (Reynolds y Seeger, 2005:45), de lo contrario al riesgo material se suma el riesgo de parálisis social. 
Cada actor dará información desde el punto de vista de su vivencia o área de conocimiento, generando su propio contexto de la magnitud del siniestro por ello, "siempre será imprescindible el relato minucioso de cómo la gente vivió ese momento, de lo que vio, oyó, sintió, supuso, imaginó y hasta soñó durante los días siguientes" (Camps y Pazos, 1996: 196); y es en el relato testimonial cuando puede derivarse hacia el espectáculo y la vulneración de derechos personales. Según la investigación de Oyanedel y Alarcón (2010: 120) sobre la televisión chilena:

El relato televisivo de la catástrofe se construye principalmente desde el dolor de las víctimas: su presencia corresponde al $49 \%$ del tiempo total destinado a las fuentes, quedando la presencia de fuentes oficiales -como gobierno, carabineros o fuerzas armadas- representada de manera muy secundaria (con porcentajes en torno al $16 \%)$ y en el caso de los expertos, de manera marginal, cuyo tiempo total en pantalla se encuentra en torno al 3\% [...] las víctimas aparecen como personas anónimas, sin identidad propia [...] más bien constituyen evidencia empírica y anónima del dolor y la catástrofe [...] Al analizar el tratamiento audiovisual [...] se observa que los recursos más utilizados fueron la reiteración de imágenes (en el $48 \%$ de las notas), el uso de primeros planos (44\%) ubicados espacialmente en un contexto de devastación material (frente a sus casas destruidas, dentro de las carpas, etc.)-, un uso excesivo de adjetivaciones (en más del $30 \%$ de las notas de carácter dramático) y la presencia de banda sonora (sobre el $20 \%$ de las notas) asociada principalmente a melodías tristes.

Es importante que se realice un sitio web donde se informe a las personas sobre el desastre, su efecto y evolución, para que su contenido tenga impacto internacional y pueda fácilmente ser observado a nivel mundial. Muchas instituciones hacen las publicaciones en sus portales en línea. En este asunto, las organizaciones que dedican su labor a Protección Civil facilitan una documentación que puede resultar trascendente en el propósito de un mejor manejo de la información. Así una de las conclusiones a tener en cuenta sería crear un organismo regional/nacional que hiciese de nodo local en el desastre y pudiese cooperar con otros organismos regionales continentales de Protección Civil ya en funcionamiento, como es el caso de Centro Regional de Información sobre Desastres. Esta organización, como plasman Canifrú Candia (2014: 11), tiene "entre sus objetivos del CRID mejorar y ampliar la recopilación, procesamiento y diseminación de información sobre desastres; crear y mantener centros de información y documentación en desastres y Promocionar la comunicación por Internet y desarrollar servicios de información electrónicos".

\section{ENTRE EL ESPECTÁCULO DEL DESASTRE Y EL IMAGINARIO DE SUPE- RACIÓN}

El pánico vivido las horas posteriores al desastre generó una situación de caos y descontrol en las poblaciones afectadas. La alerta de Tsunami como medida de prevención a un daño mayor, o por alevosía para el saqueo, disparó los nervios en algunas zonas afectadas, de donde muchas personas se alejaban. Aquellos momentos fueron de incomunicación, hasta pasadas dos horas los medios nacionales no transmitieron sobre el terremoto. Los daños afectaron a los medios locales que en su mayoría dejaron de transmitir. Según Fundamedios, "en los minutos posteriores al terremoto, tres estaciones radiales y un canal de televisión se enlazaron para brindar a Manabí la poca información oficial que tenían hasta el momento". Ese momento de urgencia los medios estaban colapsados; sin electricidad, la información llegó mientras aguantaron las baterías de los teléfonos. 
El deseo por conocer se intensifica cuando obedece a una preocupación. Con la toma de conciencia de la magnitud de lo sucedido la emoción del miedo derivó en la autoconciencia de ese sentimiento (Mora, 2015). Ante tal entendimiento, el deseo por seguridad le lleva al hombre a la praxis para liberarse de ese miedo. Así surge la necesidad por comunicarse. Si no a través de los medios, se buscan otros canales para satisfacer la comunicación de manera instintiva y espontánea. El acceso a la información tras desastres naturales se convierte en una necesidad mayor. Por una parte, el contexto conlleva la escasez informativa, y por la otra, se demanda conocer para salir del caos.

Las primeras horas de lo sucedido suele haber gran confusión, tanto en esos momentos de shock como casi dos meses después, con mayor calma, la conversación ha beneficiado a dominar el miedo (Aguagallo, 2016). Revivirlo ayuda a disminuir ese temor que ha quedado interiorizado. Una catástrofe de cierta magnitud despierta la sensibilidad social y se extiende el interés por conocer lo sucedido y afrontar la crisis.

La comunicación en momentos de crisis se convierte en un reto por recuperar el equilibrio de las vidas de los afectados. El papel de los medios resulta fundamental para reforzar los ánimos y devolver certidumbre con información veraz. Se advierte tanto en su labor psicosocial de terapia, pedagogía de prevención y restauración, como la toma de seguridad. El Manual de Fernando Ulloa (2011: 26) para la gestión del riesgo de desastre para comunicadores sociales pondera con respecto a ello que: "La producción y circulación oportuna y transparente de información contribuye a generar confianza y credibilidad". El proceso de reconstrucción depende también de la implicación de una ciudadanía formada y enérgica que dinamice de nuevo todos los aspectos de la vida. Los medios de comunicación toman un papel nuclear para la multitud afectada. Prác- ticamente la agenda mediática y la pública se enlazan, los contenidos de los medios y las preocupaciones de la gente (Sampedro, 2000) coinciden. Los efectos pasan a ocupar la totalidad de la agenda, y la opinión pública hunde su desconcierto en el escenario de la devastación. Eso inclina, como argumentan Brusi, Alfaro y González (2008), a que los responsables de medios dirijan su mirada al espectáculo o sensacionalismo, mostrando el panorama de dolor.

Bajo esa afección sobresalen historias de heroísmo que revelan personas anónimas que con sus experiencias como supervivientes dotan de fuerza al relato de superación. Si las historias de vida y las anécdotas deben ser parte de la información y existe el interés de la población, deben ser tratadas sin acudir al morbo, reparando en los códigos deontológicos del oficio. Estos autores (Brusi, Alfaro y González, 2008: 156) se formulan la siguiente pregunta retórica: “¿Por qué los medios de comunicación raramente ofrecen información sobre medidas preventivas frente a los riesgos?".

Cuando en el escenario social se ha representado el pánico, ese repliegue, rechazo o rediseño de la población frente al discurso mediático (Martín Barbero, 2012) se entorpece por el estado de conmoción social. ¿Tienen mayor impacto los efectos mediáticos en momentos de desastres? ¿La emergencia reduce al público su barrera de recepción y reinterpretación, o, en cambio, la solidaridad activa la participación de las personas? La condición de la cultura de masas como medio de la evasión (Eco, 1968), en estos momentos, se torna paradójica. La mirada se concentra en los daños y, en esa mediación, ese remplazo simboliza la vivencia y no la evasión.

Por su parte, el amarillismo insiste en evocar las historias de vida como algo que supera a la realidad. Sus fórmulas se adaptan especialmente bien al contexto de crisis o 
alarma social porque sus bases de recreación se fraguan en la fascinación y sorpresa. Causar sensación y reelaborar la realidad con relatos vagos y superficiales es aún más fácil con los artificios de técnicas y medios que ofrecen las nuevas tecnologías. Sandro Macassi Lavander (2002: 1) repara en la condición más dinámica, compleja e, incluso, transgresora del público en su recepción de la prensa amarilla en América Latina y en "las tramas culturales que ésta entreteje con las culturas de sus lectores y con la agenda pública". Este autor indica algunos factores por los cuales hay muchas personas que atienden este tipo de prensa:

- El gusto por el entretenimiento extremo por encima de la veracidad

- Por los enfoques transgresores, es decir, sin reparar en los aspectos éticos, morales o de valores (de allí el gusto o la tolerancia frente a la crónica roja, el uso del cuerpo de la mujer como objeto y la escasa preocupación por la estrictica veracidad de los hechos)

- Por la búsqueda de "horizontal social", de espacios, rostros y lenguajes similares a los suyos

- Y finalmente la preferencia por las narrativas de acción en desmedro de una actitud más analítica.

Factores, los anteriores, que ofrecen suficiente fondo para preguntarnos sobre la elección de temas y su tratamiento en el contexto que nos ocupa. En esta aproximación resultaría complicado responder a todas ellas según el objeto de estudio. Sin embargo, si nos servirán para alcanzar una primera descripción. ¿La información tras el desastre ha aportado notas para el entretenimiento? ¿Han existido enfoques trasgresores al margen de aspectos éticos? ¿Sirven los protagonistas para identificarse la población con sus protagonistas, sus espacios y lenguajes? ¿Se habría priorizado las narrativas de acción? En definitiva habría que atender a cuál de los anteriores factores responde o hubiese respondido la comunicación más amarillista durante la crisis, tanto desde la mirada al emisor como el en caso de la recepción.

Otras preguntas más generales y que sitúan a los responsables de los medios tanto públicos como privados podrían ser las planteadas tras la lectura de Umberto Eco (1968: 379) sobre la importancia de las imágenes y los elementos que han rodeado a estas:

En la comunicación por la imagen hay algo radicalmente limitativo, insuperablemente reaccionario. $Y$ sin embargo no podemos rechazar la riqueza de impresiones y de descubrimientos que en toda la historia de la civilización los razonamientos por medio de imágenes han dado a los hombres. Una prudente política cultural (mejor, una prudente política de los hombres de cultura, como corresponsales de la operación TV) será la de educar, aun a través de la televisión, a los ciudadanos del mundo futuro, para que sepan compensar la recepción de imágenes con una rica recepción de informaciones "escritas".

\section{CONCLUSIÓN}

La gestión de la comunicación por parte de los medios de comunicación es de vital importancia en situaciones de crisis, siendo estos responsables del manejo de la información en cuanto al enfoque que se pretende transmitir.

En Ecuador, horas después de la catástrofe, se conformaron distintos Comités de Operaciones Especiales (COE), en los que designaron responsables de comunicación, entre otros, y cuyas misiones iniciales y principales fueron las de conmover y reflejar la devastación y las consecuencias que había dejado el terremoto en la población. Por una parte, se pretendía informar de la situación en la que se encontraba el país, 
y, por otro lado, se daban instrucciones a la población afectada, acerca de mecanismos y métodos para prevenir accidentes con las réplicas que sucedieron al terremoto.

Una de las premisas clave que se manejaron durante la catástrofe, fue la de realizar llamados a los organismos de cooperación internacional para que llegasen las ayudas económicas y humanitarias. Es por ello que el tratamiento de las imágenes, los mensajes en redes sociales, la curación de contenidos y las retransmisiones en los medios, se han de manejar con bastante acierto, con el fin de lograr el máximo alcance posible y llegar a ser parte de un proceso de divulgación informativa a nivel internacional. Se ha demostrado el interés que despierta el sensacionalismo y la llamada prensa amarilla en las personas ante este tipo de situaciones, poniendo en tela de juicio la ética y la moral de la línea editorial del medio en cuestión, en los casos en los que se prima este fenómeno por encima del carácter meramente informativo.

Generalmente es en tiempo de crisis o catástrofe cuando los medios exaltan, con en el arte de informar, el negocio de entretener. Se debe a la por la susceptibilidad de las personas y la magnitud de un desastre o siniestro. En ese lugar, los medios no miden su forma de informar, y el único interés es crear un mayor impacto de lo sucedido, muchas veces sobredimensionando lo ocurrido y generando un relato espectacular. Es en esos momentos cuando los medios de comunicación deben convertirse en un apoyo para los afectados y las autoridades y utilizar sus recursos para informar sobre lo que se debe hacer post catástrofe para estar preparados ante otra eventualidad, e indicar con datos reales lo sucedido.

La adaptación de los medios de comunicación al entorno y a la cultura digital ha supuesto un avance importante en la fluidez y la difusión de noticias, y el acceso a estas por parte de un mayor número de población. Sin embargo, esta facilidad de divulgación informativa, puede revertir en situaciones de caos e incertidumbre, si el contenido que se maneja, no es tratado correctamente ni basado en fuentes oficiales o fiables.

El mayor impacto viral en la actualidad se encuentra en las redes sociales. En tiempos de crisis el problema radica en que muchas personas utilizan estos medios con fines de causar mayor temor a los afectados o sobrevivientes de una catástrofe y a la sociedad en general con información errónea y mal intencionada. De amplificarse el drama por medio del amarillismo se crea mayor nivel de afectación psicológica por la vulnerabilidad del pensamiento de las personas al conocer este tipo de mensajes frente a lo vivido.

Esta cultura digital presenta desventajas como la anteriormente citada, pero también ventajas; entre las últimas, está la comunicación proactiva que logró extender imágenes y testimonios de lo vivido en el país hacia todo el mundo. Lo cual permitió contar con ayuda de gobiernos de muchos países y personas que decidieron contribuir con víveres, especialistas capacitado en rescates, tecnología adecuada para facilitar la búsqueda de personas con vidas, etc. De esta manera se logró salvar a muchas personas que hoy viven para contar lo sucedido el 16A.

En definitiva, la gestión de la información, la capacidad de depurar el exceso de contenidos que se encuentran y el alcance que tienen, en muchos casos ilimitado, hacen que los medios de comunicación sean responsables públicos de la deriva de su manejo y tratamiento. , ya que se debe tener presente el poder que tiene la comunicación y la perturbación social que concibe. 


\section{REFERENCIAS}

- Aguayo, Y. (10 de junio de 2016). La mejor terapia en Bahía es la conversación. ElComercio.com Recuperado el 18 de junio de 2016, de

- http://www.elcomercio.com/actualidad/terapia-bahia-conversacion-familia-tradicion.html

- Bernardo, José María y Pellisser, Nel-lo (2010): "La 'naturalización' mediática de las catástrofes. Una aproximación crítica". Cuadernos de Información, no 26. Santiago, Pontificia Universidad Católica de Chile, pp. 103-114.)

- Brusi, D., Alfaro, P., \& González, M. (2008). Los riesgos geológicos en los medios de comunicación. El tratamiento informativo de las catástrofes naturales como recurso didáctico. Enseñanza de las Ciencias de la Tierra, 16(2), 154-166. Recuperado el 18 de junio de 2016, de https://www.researchgate. net/profile/Marta_Gonzalez15/publication/39669171_Los_riesgos_geolgicos_ en_los_medios_de_comunicacin._El_ tratamiento_informativo_de_las_catstrofes_naturales_como_recurso_didctico/links/54fd860d0cf270426d1274f9.pdf

- Camps, Sibila y pazos, Luis (1996): Así se hace periodismo. Manual práctico del periodista gráfico. Buenos Aires, Paidós. (Oyanedel y Alarcón, 2010: 120).

- Ruiz-Mora, I. La Responsabilidad Social y la gestión proactiva de riesgos. Un binomio para prevenir crisis. Recuperado de http:// s3.amazonaws.com/academia.edu. documents/34950583/21.-Ruiz-Mora.pdf?AWSAccessKeyId=AKIAJ 56 T Q JRT W S M T N P E A \& Expi res $=1469750489 \&$ Signature $=V r \% 2 F S$ V\%2FSWIGCISIr8TRMo4FnnOWA\%3D\&response-content-disposition $=$ inline\%3B\%20filename\%3DLa_Responsabilidad_Social_y_la_gestion_p.pdf

- Cerbino, M. (2005). Medios de comunicación, sociedad y cultura. Flacso, Quito. Recuperado de http://www.flacsoandes.edu.ec/comunicacion/aaa/

imagenes/publicaciones/pub_169.pdf

Canifrú Candia, G. (2014). La invisibilidad de la información en Protección Civil: reflexiones post-terremoto.

- Comfort, L. K. (2007). Crisis management in hindsight: Cognition, communication, coordination, and control. Public Administration Review,67(s1), 189-197.

- Coombs, W. T., \& Holladay, S. J. (Eds.). (2011). The handbook of crisis communication (Vol. 22). John Wiley \& Sons.

- Eco, U. (1968). Apocalípticos e integrados (séptima edición 1984). Lumen: Spain ISBN: 84-264-1039-1

- Fernández-Gordon (1992). La comunicación humana. México. McGrawHill.

- Giraud, P. (1972) La semiología. Argentina Editores, S.A. Buenos Aires.

- Fundamedios (27 de abril de 2016). Medios y periodistas, otras víctimas del terremoto en Ecuador. Fundamendios.org Recuperado el 18 de junio de 2016, de http://www.fundamedios. org/medios-y-periodistas-otras-victimas-del-terremoto-en-ecuador /

- González Herrero, A. (1998). Marketing preventivo: la comunicación de crisis en la empresa. Barcelona: Bosch.

- Hight, J.y Smith, F. (2003): Tragedias \& Periodistas. Guía para una cobertura más eficaz. New York, Dart Center for Journalism \& Trauma and Columbia University.

- Karam, T. (2011). Introducción a la semiótica de la imagen. Lecciones del portal. Portal de la Comunicación InCom-UAB. Barcelona.

- Martín-Barbero, J. (2012). De la Comunicación a la Cultura: perder el "objeto" para ganar el proceso. Signo y Pensamiento, vol. XXX, núm. 60, enero-junio, 2012, pp. 76-84. Pontificia Universidad Javeriana: Bogotá. Recuperado el 19 de junio de 2016, de http://www.redalyc. org/pdf/860/86023575006.pdf

- Macassi Lavander, S. (2002). La prensa amarilla en América Latina. Revista La- 
tinoamericana de Comunicación CHASQUI. Número 077. CIESPAL: Quito. Recuperado el 20 de junio de 2016, de http:// www.redalyc.org/pdf/160/16007704.pdf

- Mcluhan, Marshall (1962). The Gutenberg Galaxy: the making of photografic man

- Marín, F. (2000). Protocolo y comunicación. Los medios en los actos públicos. Barcelona: Bayer Hnos

- Martins, M. H. D. M. \& Spink, M. J. P. (2015). Use of disaster risk communication technologies as a preventive healthcare practice. Interface-Comunicação, Saúde, Educação, 19(54), 503-514. Recuperado de:http://www.scielo.br/pdf/icse/v19n54/ en_1807-5762-icse-19-54-0503.pdf

- Modelo psicosocial básico de las habilidades sociales de Argyle y Kendon (1967)

- Mora, F. (2015). ¿Es posible una cultura sin miedo? Madrid: Alianza Editorial. ISBN: 9788491040606

- Organización Panamericana de la salud, Susana Arroyo Barrantes, Martha Rodríguez, Ricardo Pérez, Gestión de la Información y comunicación en emergencias y desastres: Guía para equipos de respuestas, Panamá. 2009

- Piñuel, J.L. (1997). Teoría de la comunicación y gestión de las organizaciones. Madrid: Síntesis.
- Reynolds, B., \& W. Seeger, M. (2005). Crisis and emergency risk communication as an integrative model. Journal of health communication, 10(1), 43-55.

- Sampedro, V. (2000). Opinión pública y democracia deliberativa. Medios, sondeos y urnas. Madrid: Istmo

- Secretaría Nacional del Gestión de Riesgos. (2016). bResolución Na SGR048- Ecuador. Recuperado el 18 de junio de 2016, de http://www.gestionderiesgos.gob.ec/wp-content/uploads/ downloads / 2016/ 04 / Resoluci\%C3\%B3n-No.-SGR-048-2016.pdf

- Ulloa, F. (2011). Manual de gestión del riesgo de desastres para comunicadores sociales. Una guía práctica para el comunicador social comprometido en informar y formar para salvar vidas. UNESCO Representación en Perú. Recuperado el 20 de junio de 2016, de http://unesdoc.unesco.org/images/0021/002191/219184s.pdf

- Zorín, Z. M. Psicología de la personalidad. (2012). Recuperado el 18 de junio de 2016, de http://dspace.ups.edu.ec/ bitstream/123456789/6479/1/UPSQT05145.pdf 